\title{
A Simple Technique for Ovariohysterectomy in the Cat
}

\author{
M. Babu ${ }^{1 *}$, A. Krishnaswamy ${ }^{1}$, R. Nethra ${ }^{2}$ and Narasimhamurthy ${ }^{1}$ \\ ${ }^{1}$ Department of Veterinary Gynaecology and Obstetrics, ${ }^{2}$ Department of Veterinary Medicine, \\ Veterinary College, Bengaluru, Karnataka, India \\ *Corresponding author
}

\section{A B S T R A C T}

\begin{abstract}
Keywords
Ovariohysterectomy,

Cat, Flank approach,

Stab incision

Article Info

Accepted:

15 July 2018

Available Online:

10 August 2018

Ovariohysterectomy is a routine procedure that is recommended as one means of population control in cats. Different surgical approaches have been described in the literature for ovariohysterectomy in cats. Six adult queen cats of age 1-3 years, weighing $2.5-4 \mathrm{~kg}$ presented for ovariohysterectomy were selected for the study. A small incision stab technique on left lateral flank was performed. Surgical approach was evaluated by recording extent of hemorrhage, ease of location and exteriorization of ovaries and uterus, duration of surgery, post-operative complications and time required for complete wound healing. The findings of the present study established that the technique of small incision stab approach for ovariohysterectomy is easy, free of complications, requires a shorter time and also less expensive.
\end{abstract}

\section{Introduction}

The management of unowned domestic cat populations is a global problem that raises issues for individual cat welfare (Roberts $e t$ al., 2015). Ovariohysterectomy is a routine procedure that is recommended as one means of population control in cats (Levy et al., 2003). Traditionally, ovariohysterectomy in cats is routinely carried out either through a ventral midline approach or a lateral flank approach. Although ventral midline approach is absolute choice when the queen cats is pregnant or in uterine pathological condition, there is often a significantly more hemorrhage from the skin and subcutaneous tissue chances of wound inflammation or infection and due to the site being ventral, wound complications or difficult to be recognized by the owners. For this reason many veterinarians prefer carrying our ovariohysterectomy in cats through a lateral flank approach. It is particularly indicated if the queen cat is lactating and provides the advantage of observing the surgical wound from a distance and reduces potential for evisceration if would dehiscence occurs (Holly and Hardie, 2004)

The site of skin incision for flank approach is usually left lateral flank (McGrath et al., 2004) and different surgical incision patterns like horizontal flank incision, vertical flank incision and oblique flank incision have been tried for ovariohysterectomy in cats (Hoque, 1991). In general, the length of the incision 
advised for lateral flank approach is $2-3 \mathrm{~cm}$ in cats (McGrath et al., 2004; Coe et al., 2006; Rana, 2007; Kiani et al., 2014). In comparative studies Ghanawat and Mantri (1996), Shuttleworth and Smythe (2000), Coe, et al., (2006) and Rana (2007) have reported significantly shorter length of surgical incision for lateral flank approach compared to ventral midline approach. All the surgical procedures described involve the incising of the skin and abdominal muscles. Following ovariohysterectomy the muscles were sutured followed by either intradermal or skin sutures. These procedures prolong the duration of surgery has also the expenses involved for carrying out ovariohysterectomy which will be more significant particularly when stray cats are being operated. Therefore, there is a need to develop a technique where in ovariohysterectomy can be carried out through an extremely small skin incision. The present study is a report of a technique developed for ovariohysterectomy in cats which requires a very short duration, minimal trauma to the tissue and altogether avoids the use of suture materials for the abdominal muscles.

\section{Materials and Methods}

The present study was carried out on six adult female cats presented for routine ovariohysterectomy to Department of Veterinary Gynaecology and Obstetrics, Veterinary College, Bengaluru. The mean age and body weight of the animals were $1.52 \pm$ 0.21 years and $3.14 \pm 0.27 \mathrm{~kg}$ respectively. All the animals were examined ultrasonographicaly to rule out pregnancy and a general examination was carried out to confirm that they were fit for pregnancy. Every animal was fasted for at least 8-12 hours prior to surgery and water was withheld for at least six hours preoperatively. The cats were premedicated with Atropine sulphate (0.04 mg/kg body weight) subcutaneously. Anaesthesia was induced by combination of
Xylazine Hydrochloride (1 $\mathrm{mg} / \mathrm{kg}$ body weight) and Ketamine Hydrochloride (25 $\mathrm{mg} / \mathrm{kg}$ body weight) both drugs were loaded into the same syringe and had given intramuscularly to effect.

The animal was put on right lateral recumbency and the bladder was emptied by manual compression as shown in (Fig. 1) as the distended bladder may hinder locating and exteriorization of uterus. The entire left flank was clipped with a surgical clipper blade No. 40 and the area was scribed alternatively with $4 \%$ Chlorexidine solution and surgical spirit for at least 5 minutes and finally painted with $7.5 \%$ povidine iodine. Surgical site was determined approximately as the intersection of two finger breadth measured from the last rib, one finger from the lumbar processes and two finger breadth measured from fold of flank (Fig. 2). The surgical site was covered with sterile surgical drapes and using a No.15 Bard parker blade, a five $\mathrm{mm}$ long oblique incision was made through the skin down to the level of the muscle, but not through the muscle layer.

Following the skin incision the entire left abdomen was grasped between thumb and fore finger and slight pressure applied so as to distend the left abdominal wall (Fig. 3). Using mosquito artery forceps, a stab incision was made at point of nick incision holding the forceps at about $45^{\circ}$ angle to the skin incision and the mosquito forceps was directed into abdominal cavity by applying mild pressure at the point where mosquito forceps were held. The entry of artery forceps into the cavity was confirmed by a slight resistance when the artery forceps came in contact with peritoneum and a small pop sound as the artery forceps made its way through peritoneum. Following entry into the peritoneum, the blades of the artery forceps were opened slightly in order to slightly enlarge the stab incision on muscle and 
peritoneum. The uterus in cats is generally located immediately below the peritoneum at this particular surgical site and therefore the organ found immediately below the peritoneum was gently grasped with the mosquito forceps and slowly brought out through the stab incision. The uterine horn and ovary was completely brought out through the skin incision site (Fig. 4). The ovarian peduncle was legated with 2-0 chromic cat gut and ovarian peduncle was severed. Following complete resection of ovary uterine horn was traced to the bifurcation and the contralateral uterine horn was located by grasping with mosquito artery forceps and gentle traction applied to expose horn and the ovary completely. Surgical resection was made after proper ligation of ovarian peduncle. Following resection of both ovaries, two uterine horns were completely lifted and gentle traction applied caudally so as to expose the cervix and resection of cervix was made after application of ligature (Fig. 5). The incised cervical end was dropped into the abdominal cavity and surgical site was inspected for evidence of bleeding. No attempt was made to suture to close the abdominal muscles or skin. The incised site was covered with a sterile bandage. All animals had received postoperative care as per the standard recommendations.

The following parameters were recorded in each animal;

Extent of hemorrhage

Ease of location and exteriorization of ovaries and uterus

\section{Duration of surgery}

Post-operative complications

Time required for complete wound healing Results and Discussion
In the present study, ovariohysterectomy was attempted through a skin incision as small as five millimeter. In most other reports, the skin incision on the left flank is usually $2-3 \mathrm{~cm}$ (McGrath et al., 2004; Coe et al., 2006; Rana, 2007; Kiani et al., 2014). While a longer skin incision will provide better exposure and ease of locating and exteriorizing the uterus, it could also be associated with greater degree of bleeding and tissue trauma. In the present study on the other hand the uterus was approached through a skin incision as small as five millimeter and none of the animals exhibited any bleeding either after skin incision.

In standard left flank approach, following skin incision the abdominal muscles are also incised and peritoneal cavity is then entered. This sort of approach would require suturing of the abdominal muscles after the completion of the surgical procedures. The incision of the abdominal muscles could also contribute to hemorrhage.

In the present study on the other hand the abdominal muscles were not surgically incised but abdominal cavity was entered by stabbing a mosquito artery forcep through the abdominal muscles and peritoneum after making the skin incision. This technique was carried out to avoid the incision of the abdominal muscles and to prevent bleeding associated with incision.

A stab incision of abdominal muscles employed in present study was also found not to cause any significant hemorrhage from the site. The uterus could be easily grasped and exteriorized without any difficulty and the both the ovaries could be easily legated. No operative complications were observed in any of six animals subjected to spaying using the procedure described. 
Fig.1 Manual extraction of the urine for spaying at left lateral flank

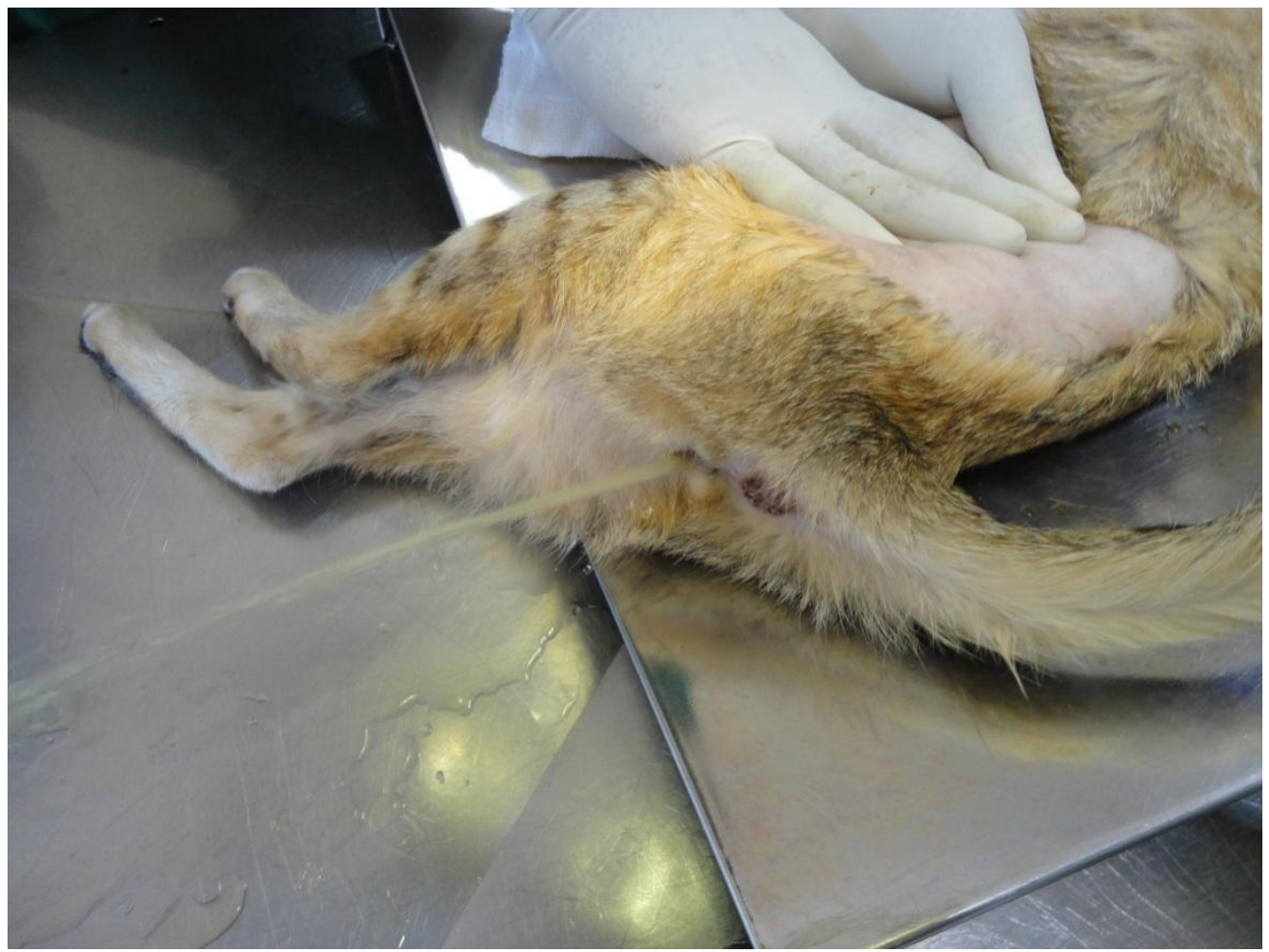

Fig.2 Skin incision -left flank approach

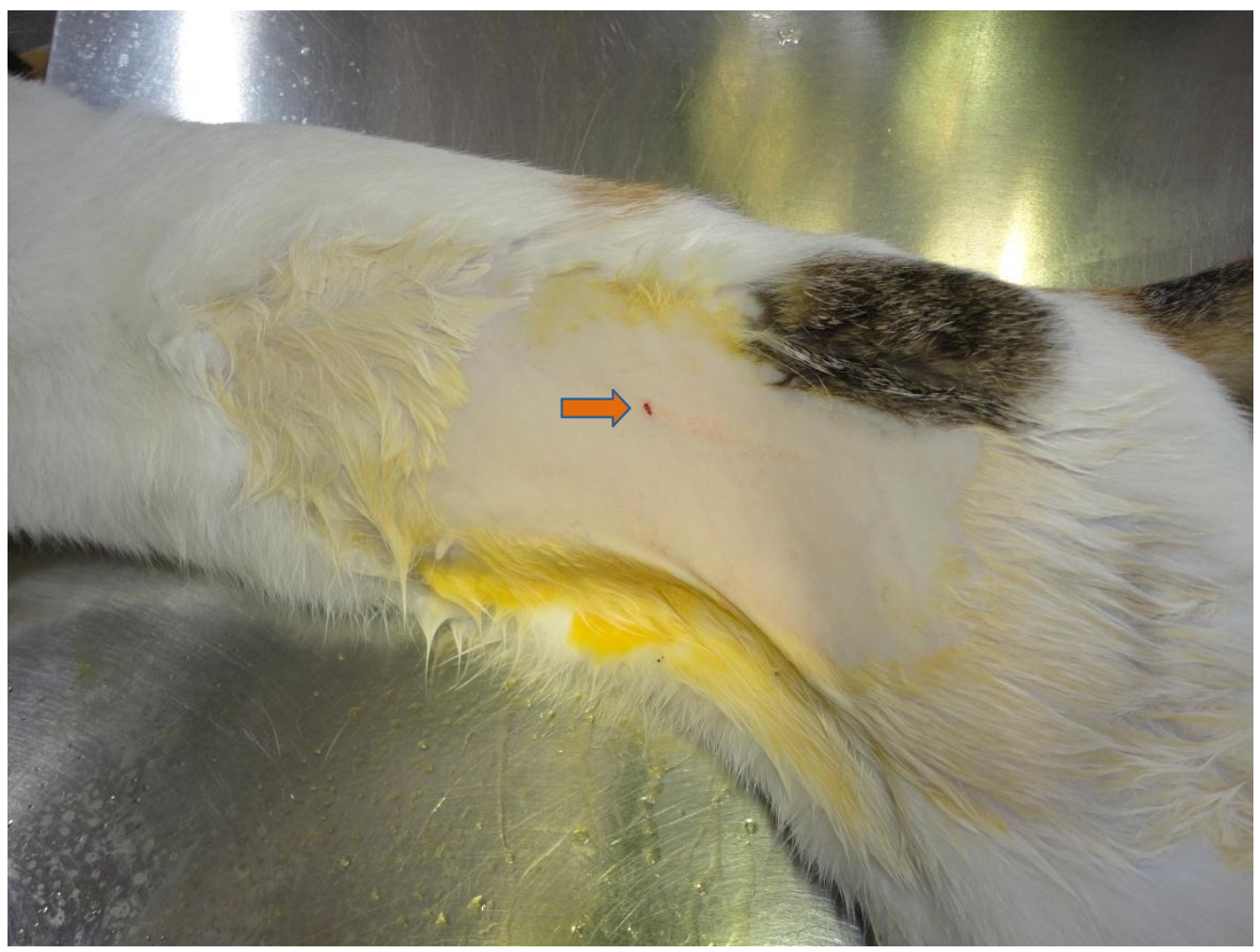


Fig.3 Stab incision being made to enter into the peritoneal cavity - left lateral flank approach

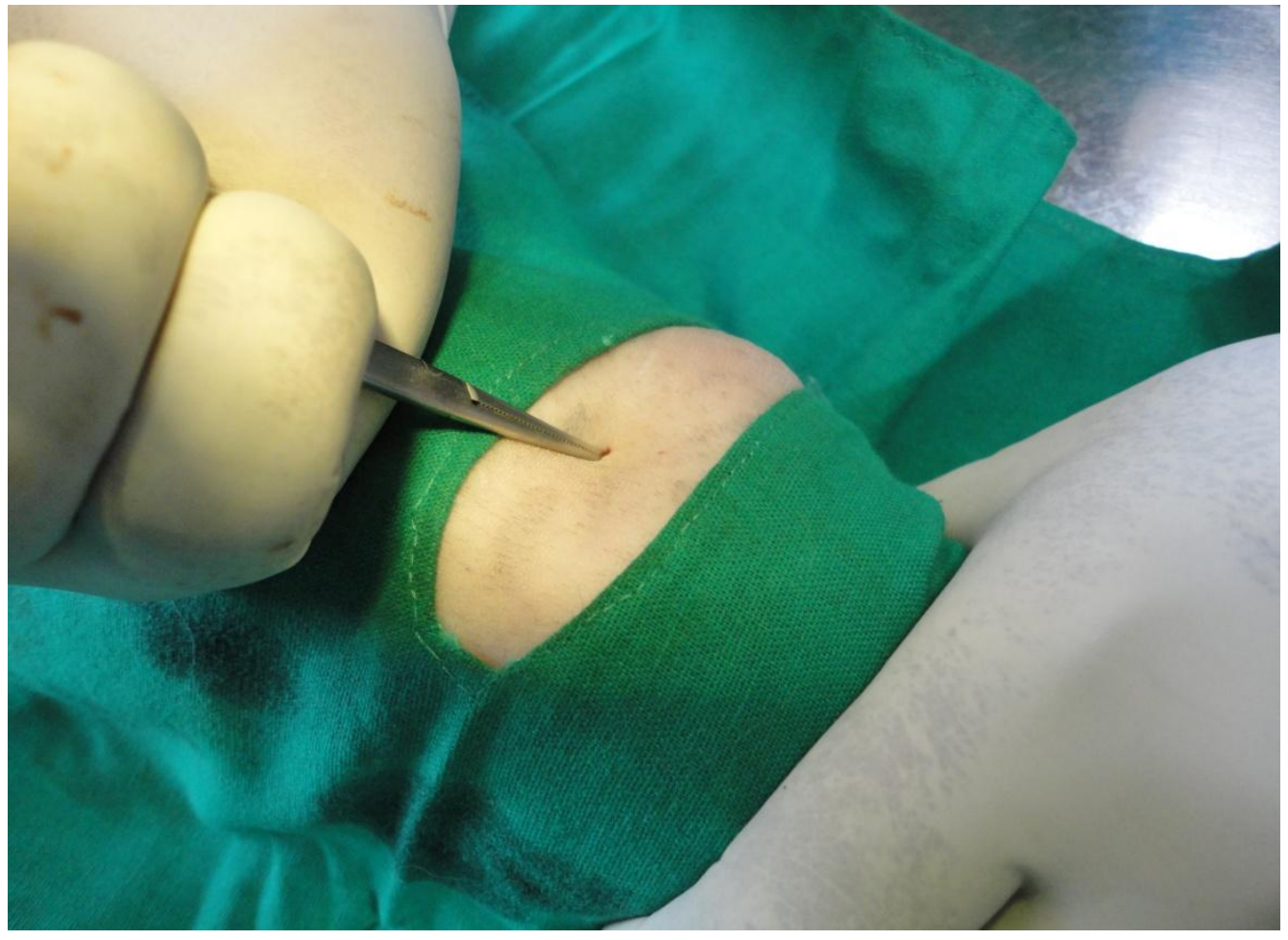

Fig.4 Exteriorization of uterine horns and ovaries for ligation through stab incision - left lateral flank approach

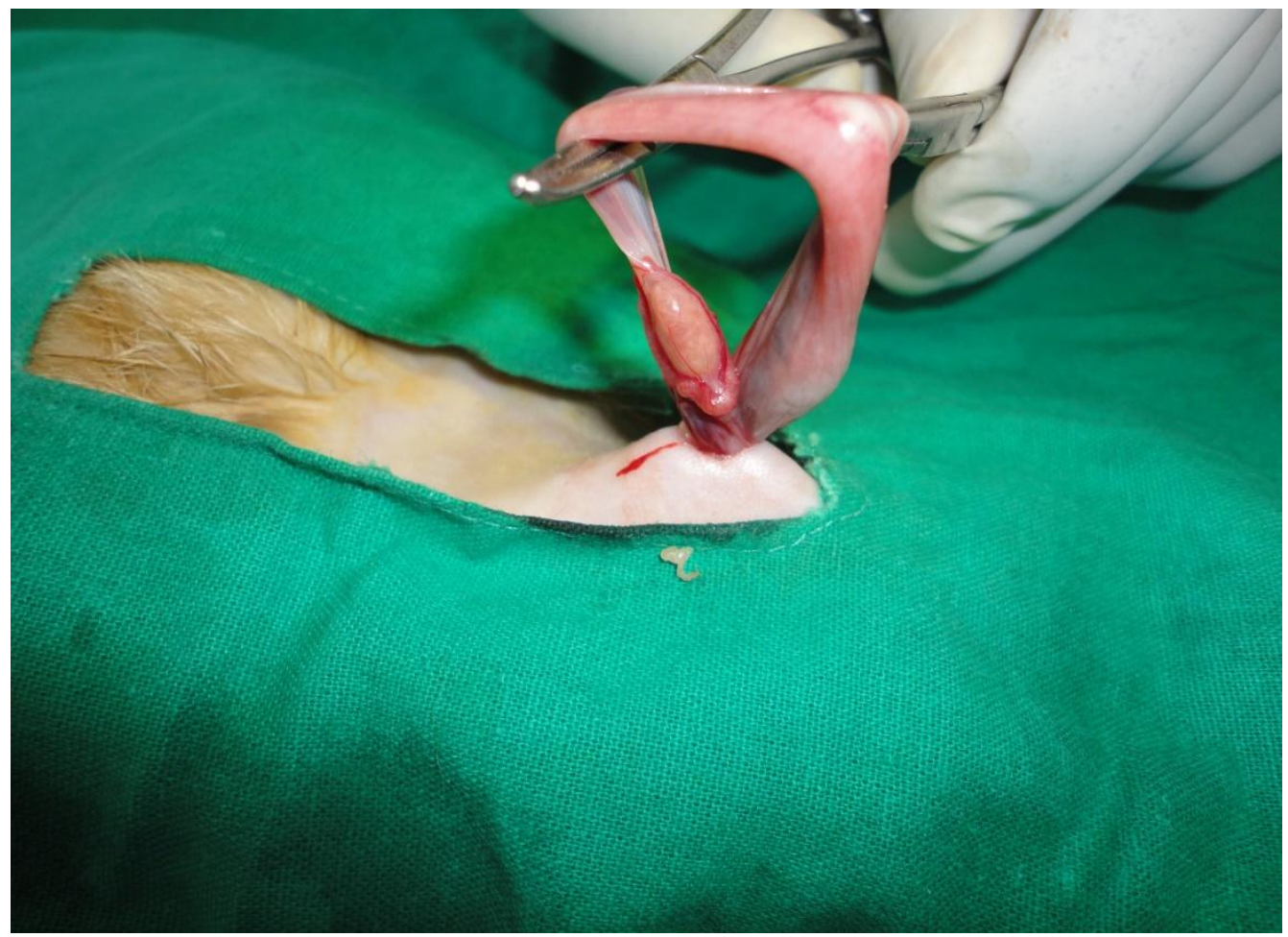


Fig.5 Exteriorization of the cervix for ligation - left lateral flank approach

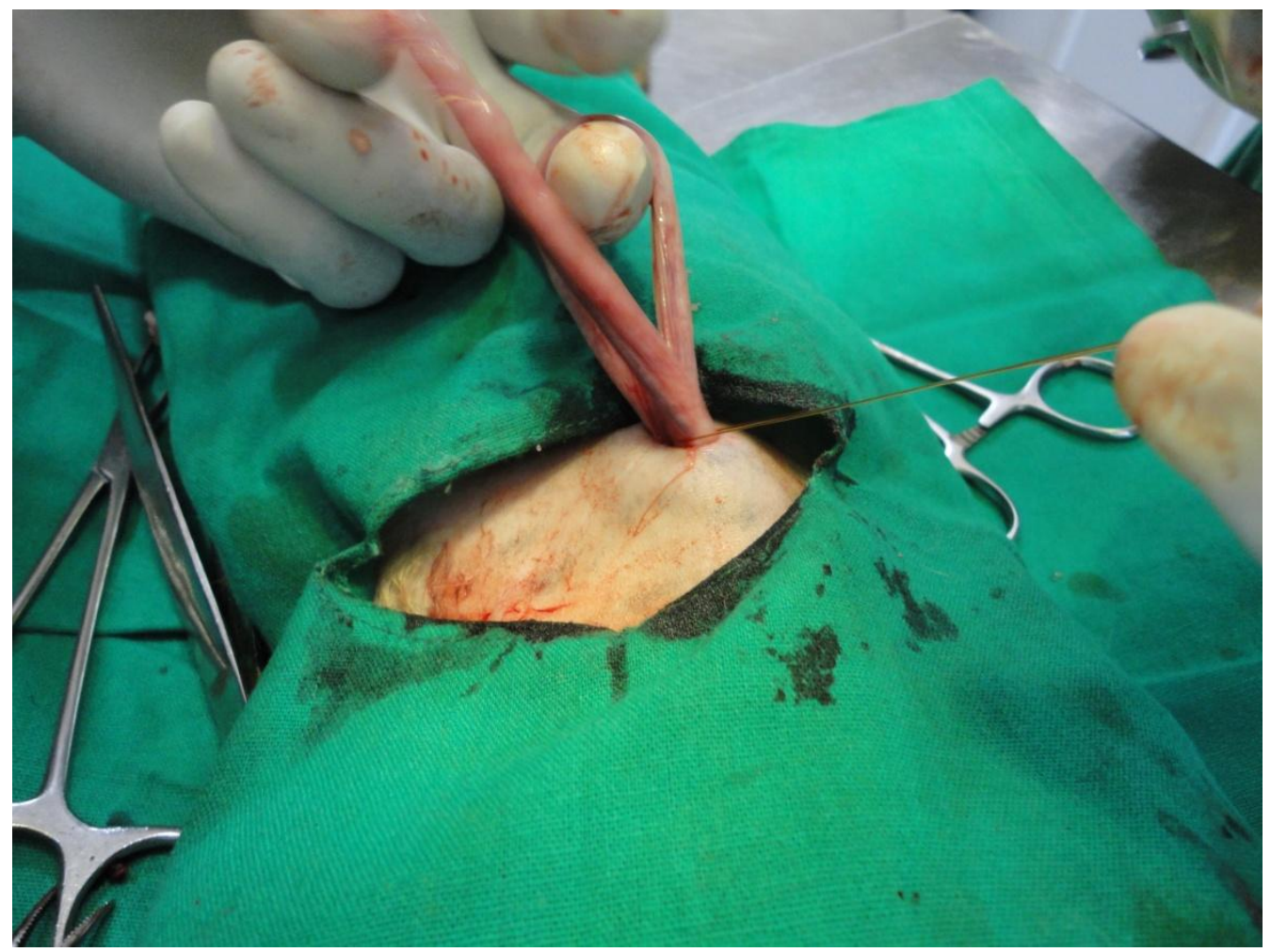

Fig.6 Surgical wound after the completion of spaying procedure - left lateral flank approach

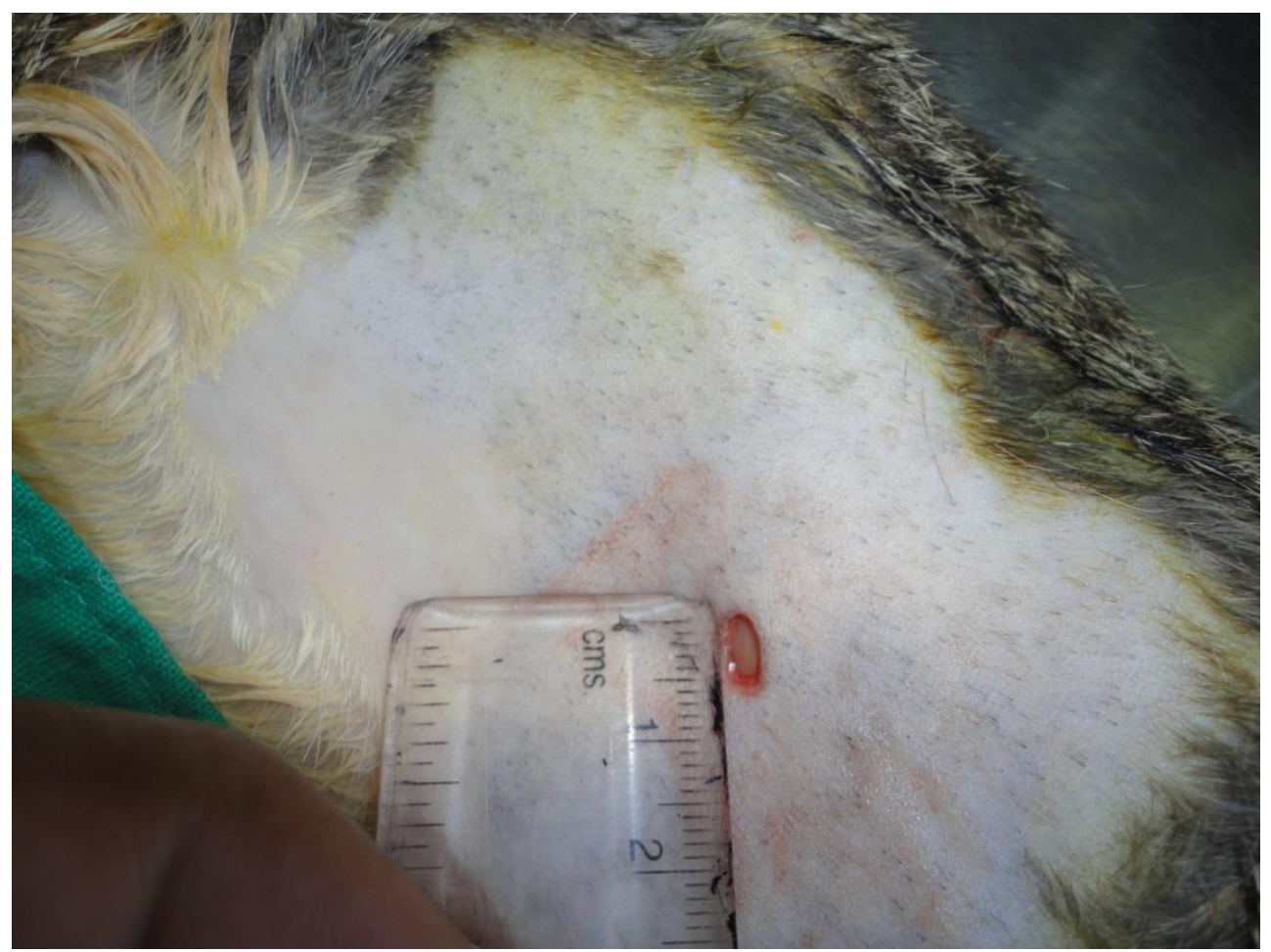


Fig.7 Appearance of the surgical wound at $48 \mathrm{hr}$ after spaying through left lateral flank approach

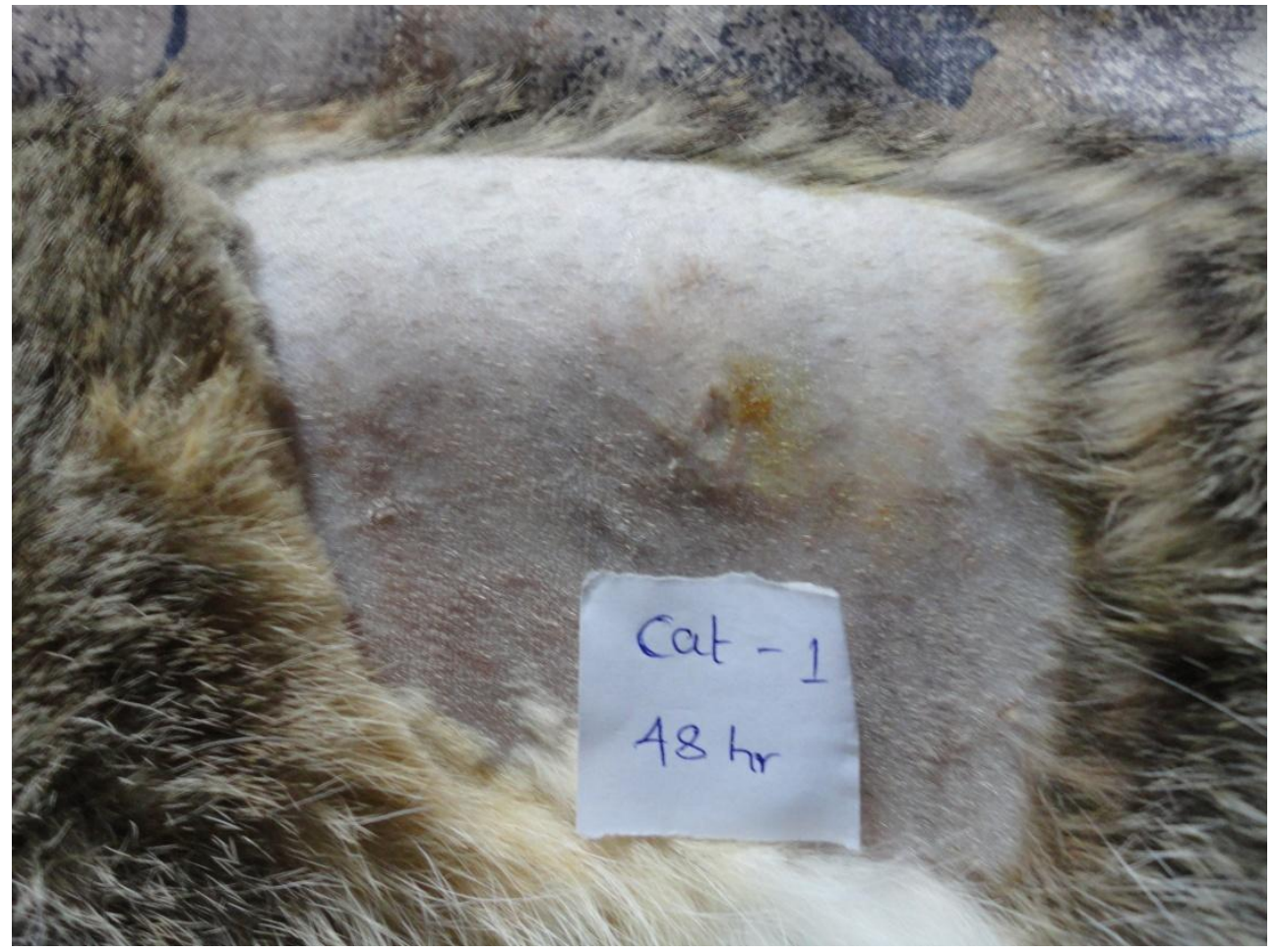

Following ovariohysterectomy the abdominal muscles were left unsutured as only a stab incision was made through the muscles and if left unsutured it was most unlikely that any kind of evisceration of the abdominal organs can occur because of the size of the incision. Additionally, the lower abdominal muscles would automatically cover the other layers. The present study didn't record any postoperative complications such as evisceration, wound edema and abnormal discharges from the wound. The surgical wound had completely healed by day 7 post surgery in experimental animals. The mean time taken for the entire surgery was recorded as $6.7 \pm$ 0.48 min (Fig. 6 and 7).

A thorough scanning of the literature revealed that there is only one other report which describes carrying ovariohysterectomy in cats using stab incision (Rana, 2007). However, the skin incision that made was as long as 2.2 $\mathrm{cm}$ and a tooth less thumb forceps was forced through the abdominal muscles and peritoneum as compared to a five millimeter incision made in the present study and use of mosquito artery forceps for entry into abdominal cavity.

The surgical procedure therefore could be carried out in a significantly shorter time and considerably reduced the expenses incurred towards the surgery. The results of the present study established that the technique of small incision stab approach for ovariohysterectomy is easy, free of complications, requires a shorter time and also less expensive.

\section{References}

Coe, R.J., Grint, N.J., Tivers, M.S., Moore, A.H. and Holt, P.E. 2006. Comparison of flank and midline approaches to the ovariohysterectomy of cats. Vet. Rec. 159: 309-313.

Ghanawat, H.G. and Mantri, M.B., 1996. Comparative study of various 
approaches for ovariohysterectomy in cats. IVJ. 73: 987-988.

Holly, M.G. and Hardie, R.J. 2004. Lateral Flank Approach for Ovariohysterectomy in Small Animals. Vet. Med. Small Anim. Clin. 70 (5): 569-573.

Hoque, M. 1991. Comparative study of various approaches to feline ovariohysterectomy. Ind. J. of Vet. Surg. 12: 29-30.

Kiani, F.A., Kachiwal, A.B., Shah, M.G., Nizamani, Z.A., Khand, F.M., Lochi, G.M., Haseeb, A., Khokhar, A.M., Oad, A. and Ansari, M.I. 2014. Comparative Study on Midline and Flank Approaches for Ovariohystrectomy in Cats. Journal of Agriculture and Food Technology, 4(2): 21-31.

Levy, J. 2004. Feral cat management. In: Miller, L. and Zawistowski, S. (Ed.), Shelter medicine for veterinarians and staff. Blackwell Publishing., pp- 381385.

McGrath, H., Hardie, R.J. and DAVIS, E. 2004. Lateral flank approach for ovariohysterectomy in small animals. Compend Contin Educ Small Anim Pract., 26: 922-30.

Rana, M.A. 2007. Comparative study of flank vs midline approach for ovariohysterectomy in cats. UVAS, Lahore (Pakistan), pp-75.

Roberts, M.L., Beatty, J.A., Dhand, N.K. and Barrs, V.R. 2015. Effect of age and surgical approach on perioperative wound complication following ovariohysterectomy in shelter-housed cats in Australia. Journal of Feline Medicine and Surgery, Open Reports, 1(2): $1-4$.

ShuttleWorth, A.C. and Smythe, R.H. 2000. Surgical conditions of female organs. Clinical Veterinary Surgery. (2). Green World Publishers., India. pp. 484-490.

\section{How to cite this article:}

Babu, M., A. Krishnaswamy, R. Nethra and Narasimhamurthy. 2018. A Simple Technique for Ovariohysterectomy in the Cat. Int.J.Curr.Microbiol.App.Sci. 7(08): 2554-2561. doi: https://doi.org/10.20546/ijcmas.2018.708.262 